\title{
Degradabilidade de gramíneas, fermentação e protozoários no rúmen de bovinos em dietas com diferentes aditivos
}

\author{
Degradability of grasses, ruminal fermentation and protozoa in beef cattle on diet with \\ different additives
}

\section{COSTA, Francisco Antonio Andrade ${ }^{1}$; FERNANDES, Lauriston Bertelli² ${ }^{2}$ GARCIA, Valerio Pagliarini ${ }^{3}$; SOARES, Weber Vilas Boas ${ }^{4}$; FRANZOLIN, Raul ${ }^{5 *}$}

\author{
${ }^{1}$ Autônomo , São João da Boa Vista, São Paulo, Brasil. \\ ${ }^{2}$ Premix, Patrocínio Paulista, São Paulo, Brasil. \\ ${ }^{3}$ Autônomo, Valinhos, São Paulo, Brasil. \\ ${ }^{4}$ Instituto de Zootecnia, Nova Odessa, São Paulo, Brasil. \\ ${ }^{5}$ Universidade de São Paulo, Faculdade de Zootecnia e Engenharia de Alimentos, Departamento de \\ Zootecnia, Pirassununga, São Paulo, Brasil. \\ *Endereço para correspondência: rfranzol@usp.br
}

\section{RESUMO}

Quatro bovinos, com fistulas ruminais, foram alimentados em Quadrado Latino com os tratamentos compreendendo a adição diária no rúmen de: levedura $(5 \mathrm{~g})$, monensina $(200 \mathrm{mg})$, Fator P (3g) e controle. Foram determinadas a Degradabilidade in situ de três capins tropicais (Tifton-85, Brachiaria e Mombaça e silagem de Mombaça), o pH ruminal, produção de ácidos graxos voláteis, N-amoniacal e população de protozoários. Não foi observada interação significativa entre tratamentos e capins e diferenças significativas entre os tratamentos, exceto na fração $b$ da Brachiaria e silagem de Mombaça. O Mombaça apresentou alta solubilidade da MS e da FDN em relação aos demais capins e a Brachiaria maior solubilidade da PB. O processamento do Mombaça na forma de silagem promoveu redução fração solúvel e degradabilidades potencial (DE) e efetiva (DE) da MS e FDN e aumento da fração solúvel e DE da PB. A monensina promoveu menor produção de ácido acético, maior de propiônico e menor acético:propiônico em relação a controle. A levedura e Fator $\mathrm{P}$ apresentaram maior concentração total de AGCC que a monensina e controle. A monensina promoveu aumento de protozoários Diplodiniinae em relação à dieta controle, mas não houve diferença na contagem de Entodinium e de total de ciliados entre os tratamentos. Capins tropicais na forma de feno e de silagem apresentam diferentes degradabilidade ruminal não sendo influenciados por aditivos na dieta, com exceção da monensina no capim Brachiaria e silagem de Mombaça, mas estes afetam a fermentação e a população de protozoários no rúmen.

Palavras-chave: fator $\mathrm{P}$, forragens tropicais, levedura, metabolismo ruminal, monensina

\section{SUMMARY}

Four cattle rumen fistulae were fed on Latin Square with four treatments including the daily addition into rumen of: yeast $(5 \mathrm{~g})$, monensin (200mg), Fator P (3g) and control. In situ degradability was determined with three tropical grasses: Tifton-85, Brachiaria, Mombasa and Mombasa silage, as well as ruminal $\mathrm{pH}$, production of volatile fatty acids, ammonia-N and protozoa population. There was no significant interaction between treatment and grasses and significant differences between treatments, except in fraction $b$ of Brachiaria and Mombasa silage. The Mombasa showed high solubility of DM and NDF compared to other grasses and Brachiaria higher solubility of CP. Processing of Mombasa as silage promoted reduction of soluble fraction and potential (PD) and effective degradabilities (ED) of DM and NDF and increased soluble fraction and ED of $\mathrm{CP}$. Monensin produced lower production of 
acetic acid, higher of propionic and lower acetic: propionic acid. Yeast and Fator $\mathrm{P}$ showed higher total acids concentration than monensin and control. Diplodiniinae protozoa was increased with monensin compared to the control diet, but there was no difference in Entodinium and total ciliates between treatments. Tropical grasses in the form of hay and silage have different ruminal degradability not being influenced by additives in the diet, but these affect fermentation and protozoa population in the rumen.

Keywords: fator P, rumen metabolism, tropical forages, yeast, monensin

\section{INTRODUÇÃO}

Aditivos em dietas de ruminantes tais como leveduras, probióticos e ionóforos, têm sido utilizados visando atuar na relação simbiótica entre os microrganismos no rúmen para maximização do processo fermentativo e da eficiência alimentar, melhorando as funções ruminais com aumento do fluxo de nitrogênio ao duodeno e redução da emissão de metano, principalmente em animais que recebem dietas ricas em amido (MITSUMORI \& SUN, 2008). Entretanto, há necessidade de maiores informações sobre os efeitos do uso de aditivos em dietas ricas em volumosos no metabolismo ruminal e na população de protozoários, já que esses microrganismos estão direta e indiretamente relacionados com as ações de bactérias e fungos no uso de substrato no rúmen, principalmente devido ao processo de engolfamento de bactérias e competição por nutrientes. (WILLIAMS \& COLEMAN, 1992)

Efeitos benéficos das leveduras no rúmen, particularmente a Saccharomyces cerevisiae estão associados com aumento de bactérias celulolíticas na biomassa microbiana e melhoria na digestão da fibra (MOSONI et al., 2007); estabilização do $\mathrm{pH}$ e prevenção de acúmulo de lactato no rúmen (FONTY \& CHAUCHEYRAS-DURAND, 2006).

Os ionóforos atuam como inibidores de bactérias gram positivas no rúmen promovendo redução da produção de gás metano (GUAN et al., 2006). Aditivos orgânicos contendo ácidos graxos essenciais, oleico, linoleico e linolênico (Fator $\mathrm{P}$ ), como o Fator $\mathrm{P} \AA$, se tem mostrado promover melhorias no ambiente ruminal refletindo no desempenho de bovinos de corte em pastagem (FERNANDES et al., 2008).

Desde a década de 1960 vários estudos têm focado a eficiência produtiva de dietas contendo enzimas, controladores da metanogênese, ionóforos, probióticos e antibióticos na nutrição de ruminantes. Porém, o aumento da segurança alimentar devido ao uso de antibióticos e outros estimulantes de crescimento na alimentação animal tem levado a comunidade científica no foco de alternativas como uso de aditivos orgânicos que promovam melhoria na eficiência alimentar, sem prejuízos à qualidade dos produtos animal e ao meio ambiente.

Aditivos podem ser facilmente utilizados na alimentação de ruminantes como suplementos adicionados em rações concentradas, tanto para animais à pasto como em confinamento.

$\mathrm{O}$ objetivo do presente trabalho foi avaliar o metabolismo ruminal envolvendo a degradabilidade de três gramíneas (três como feno e uma silagem), a produção de ácidos graxos de cadeia curta e de nitrogênio amoniacal, o $\mathrm{pH}$ e a população de protozoários ciliados no rúmen $\mathrm{em}$ bovinos zebuínos alimentados com dietas com alto nível de volumoso e três diferentes aditivos (levedura, monensina e Fator P). 


\section{MATERIAL E MÉTODOS}

Quatro bovinos zebuínos da raça Nelore, com peso vivo médio inicial de $262 \mathrm{~kg}$ e cânulas permanente no rúmen, foram utilizados num experimento em Quadrado Latino (4 x 4) com períodos de 21 dias cada, sendo 16 dias de adaptação e cinco de coletas. $\mathrm{O}$ experimento foi conduzido de acordo com as normas de bem-estar animal. Os animais foram alojados em baias individuais providas de cochos para a alimentação, com água e suplementação mineral disponíveis à vontade.

A alimentação foi realizada duas vezes ao dia com uma ração basal composta de $75 \%$ de feno de capim Tifton- 85 de qualidade média com $9,19 \%$ de proteína bruta (PB) e $25 \%$ de uma ração concentrada comercial contendo $20 \%$ de PB oferecida na quantidade de $2,8 \%$ do peso vivo médio em MS. Os tratamentos consistiram na adição no rúmen, via cânula, sempre antes da primeira alimentação, de três diferentes aditivos e um tratamento testemunha, assim designados: $\mathrm{CON}=$ controle (sem aditivo); LEV $=$ Levedura (Saccharomyces cerevisiae "Beef Sac") (5g/animal/dia); MON = Monensina sódica $(200 \mathrm{mg} / \mathrm{animal} / \mathrm{dia})$ e Fator $\mathrm{P}=$ Fator $P ®(3 \mathrm{~g} /$ animal/dia) consistindo de mistura de ácidos graxos essenciais.

A degradabilidade da matéria seca (MS) e da fibra em detergente neutro (FDN) foram determinadas em amostras de três gramíneas tropicais na forma de feno: Tifton-85 (Cynodonspp.), Brachiaria (Brachiaria brizantha cv. Marandu) e Mombaça (Panicum maximum Jacq. Mombaça), sendo a última na forma in natura e de silagem. As amostras foram adicionadas em sacos de náilon e incubadas no rúmen, seguindo as características da técnica de degradabilidade in situ (ORSKOV et al., 1980). Os capins apresentaram teores médios de PB e FDN com base na MS, respectivamente: Tifton- 85 $(9,19 \%$ e $77,68 \%)$, Brachiaria $(2,8 \%$ e $74,26 \%)$, Mombaça (11,64\% e 63,94\%) e silagem de Mombaça $(7,35 \%$ e $70,98 \%)$. Os sacos de náilon (Ankon ${ }^{\mathrm{TM}}$ ) contendo $7 \mathrm{~g}$ de amostras foram devidamente pesados e incubados no rúmen por $6,12,24,48,72$ e 96 horas de maneira reversa, sendo lavados todos ao mesmo tempo em um tanquinho eletrodoméstico comercial adaptado e em seguida foram secos em estufa de circulação forçada de ar a $65^{\circ} \mathrm{C}$ por 72 horas.

As porcentagens de desaparecimento dos nutrientes dos sacos de náilon em cada tempo de incubação foram ajustadas utilizando-se a equação nãolinear: DP $=\mathrm{a}+\mathrm{b}\left(1-\mathrm{e}^{\text {-ct }}\right)$; onde DP é a degradabilidade potencial; "a" é o intercepto da curva e representa a fração solúvel; "b" a fração insolúvel, mas potencialmente degradável no rúmen e "c" a taxa de degradação por hora (ORSKOV et al., 1980). A degradabilidade efetiva (DE) foi estimada como: $\mathrm{DE}=\mathrm{a}+[\mathrm{b} *(\mathrm{c} /(\mathrm{c}+\mathrm{k}))]$, assumindo a taxa de passagem do conteúdo ruminal de $\mathrm{k}=0,02 /$ hora (DE002), tendo em vista o alto nível de volumoso da dieta.

Amostras de líquido ruminal foram colhidas, via cânula, com uso de uma bomba de vácuo adaptada, para determinações do $\mathrm{pH}$, nitrogênio amoniacal e ácidos graxos de cadeia curta (AGCC), no último dia de cada período antes da primeira alimentação (0 hora) e 2, 4 e 8 horas após. $\mathrm{O}$ pH foi determinado com medidor eletrônico de $\mathrm{pH}$, devidamente calibrado, imediatamente após a retirada do conteúdo ruminal. A quantificação do nitrogênio amoniacal foi realizada por colorimetria, pelo método de reação hipoclorito-fenol (WEATHERBURN, 
1967) e de AGCC por cromatografia gasosa. Para as análises de nitrogênio amoniacal, foram colhidas amostras de $2 \mathrm{~mL}$ de liquido ruminal e adicionado 1 $\mathrm{mL}$ de ácido sulfúrico $1 \mathrm{~N}$. Amostras de $10 \mathrm{~mL}$ de conteúdo ruminal contendo parte sólida e líquida foram colhidas manualmente durante dois dias consecutivos no final de cada subperíodo experimental, sempre antes da alimentação e fixadas em igual volume de solução de formoldeido $1: 2$ $(18,5 \% \mathrm{v} / \mathrm{v})$ para identificação e contagem de protozoários ciliados no rúmen por microscopia ótica (DEHORITY, 2003). Foram avaliados os seguintes gêneros de protozoários ciliados: Entodinium, Epidinium, Isotricha, Dasytricha, Charonina e os pertencentes à subfamília Diplodiniinae a qual incluem: Diplodinium, Eudiplodinium, Ostracodinium, Metadinium, Enoploplastron e Polyplastron.

Os dados obtidos foram analisados estatisticamente em programa computacional utilizando-se efeitos específicos com o módulo GLM (STATSOFT, 2012), de acordo com o modelo: $y i j k=m+p i+a j+t k(i j)+$ eijk , onde yijk = valor observado na unidade experimental que recebeu o tratamento $\mathrm{k}$ (no período i e animal j); $\mathrm{m}=$ efeito da média geral; $\mathrm{pi}=$ efeito do período $i=1,2,3$ e 4 ; aj = efeito do animal $\mathrm{j}=1,2,3$ e $4 ; \mathrm{tk}(\mathrm{ij})=$ efeito do tratamento $k=1,2,3$ e 4 aplicado no período $\mathrm{i}$ e animal $\mathrm{j}$; eijk $=$ erro aleatório. $\mathrm{O}$ teste de LSD foi utilizado para comparação de médias em 5\% de significância.

\section{RESULTADOS E DISCUSSÃO}

Houve diferenças significativas entre os tratamentos e entre os capins avaliados na degradabilidade ruminal dos nutrientes, entretanto, foi observado interação significativa entre tratamentos e os capins, para: (1) a fração potencialmente degradável (b) da MS do capim Brachiaria nos animais suplementados com a monensina $(57,91 \%)$ e com levedura $(59,19 \%)$ foi menor $(\mathrm{P}<0,05)$ em relação à dieta sem uso de aditivos $(63,94 \%)$ enquanto que o tratamento Fator $\mathrm{P}(62,12 \%)$ não diferiu entre os demais (Tabela 1); (2) houve diminuição da fração (b) da MS da silagem de Mombaça com a monensina $(53,47 \%)$ em relação a dieta controle $(57,20 \%)$, levedura $(56,71 \%)$ e Fator P (57,96\%) (Tabela 1); (3) a taxa de degradação da proteína bruta do Brachiaria foi menor nos tratamentos Controle e Fator P $(2,43 \% / \mathrm{h})$ do que em monensina $(4,93 \% / h)$ e levedura $(4,37 \% / \mathrm{h})$ (Tabela 2); (4) a taxa de degradação da $\mathrm{PB}$ da silagem de Mombaça foi maior com a monensina $(6,56 \% / \mathrm{h})$ em relação ao controle $(2,59 \% / h)$, o qual não diferiu com a levedura $(3,87 \% / \mathrm{h})$ e com o Fator $\mathrm{P}$ $(3,88 \%)$ (Tabela 2); (5) A monensina promoveu maior taxa de degradação (c) da PB com o Brachiaria e com a silagem de Mombaça $(p<0,05)$ em relação ao tratamento sem aditivos mas sem efeito para o Tifton-85; (6) a fração $b$ da FDN da silagem de Mombaça foi menor com adição de monensina $(55,71 \%)$ comparada com suplementação controle $(60,75 \%)$, com levedura $(60,32 \%)$ e com Fator $\mathrm{P}$ $(61,70 \%)$ (Tabela 3$)$.

Diferenças significativas foram observadas em todos os parâmetros da cinética de degradabilidade em todos os nutrientes entre os quatro capins avaliados. A fração solúvel (a) da MS e FDN foi significativamente mais elevada no capim Mombaça com menor valor da fração potencialmente degradável (b), promovendo aumento 
da degradabilidade efetiva da MS $(61,31 \%)$ e da FDN (59,17\%) em relação os demais capins avaliados (Tabelas 1 e 3). Houve redução da fração solúvel (a) da MS e da FDN e aumento da PB com o processo de ensilagem do capim Mombaça em relação ao mesmo capim na forma natural. Assim, houve redução na degradabilidade efetiva da MS (de 61,31 para 50,87\%) e da FDN (de 59,17 para 48,05\%) e aumento da PB (de $67,86$ para $72,15 \%)$ com o processamento do capim Mombaça na forma de silagem (Tabelas 1, 3 e 2, respectivamente). Esse achado corrobora com os baixos valores observados na degradabilidade potencial da MS, de $60,8 \%$ e da proteína bruta, de $75,2 \%$ da silagem de capim Brachiaria brizantha (PIRES et al., 2010). Entretanto, as degradabilidades efetivas da MS e FDN do capim Mombaça foram maiores que àquelas observadas com 0 mesmo capim de $40,8 \%$ e $29 \%$, respectivamente (PRADO et al., 2004). Já, o valor médio obtido para a DE002 da MS do capim Tifton 85 (55,23\%) está próximo ao observado por Martins et al. (2007) com Tifton 85 com 30 dias de crescimento vegetativo $(61,8 \%)$.

Tabela 1. Degradabilidade in situ da matéria seca de diferentes gramíneas em bovinos zebuínos recebendo dietas com diferentes aditivos

\begin{tabular}{|c|c|c|c|c|c|}
\hline \multirow{2}{*}{ Item } & \multicolumn{5}{|c|}{ Cinética da degradação1 } \\
\hline & $\mathrm{a}(\%)$ & $\mathrm{b}(\%)$ & $\mathrm{c}(\% / \mathrm{h})$ & $\mathrm{DP}(\%)$ & DE002 (\%) \\
\hline \multicolumn{6}{|l|}{ Tifton-85 } \\
\hline Controle & 9,44 & 69,82 & 4,7 & 79,26 & 58,13 \\
\hline Levedura & 11,06 & 67,39 & 4,18 & 78,44 & 56,37 \\
\hline Monensina & 10,30 & 68,70 & 3,95 & 79,00 & 55,49 \\
\hline FAP & 14,02 & 67,57 & 3,78 & 81,59 & 57,93 \\
\hline \multicolumn{6}{|l|}{ Braquiarão } \\
\hline Controle & 7,47 & $63,94^{\mathrm{a}}$ & 4,25 & 71,40 & 50,88 \\
\hline Levedura & 11,44 & $59,19^{\mathrm{b}}$ & 3,97 & 70,64 & 50,65 \\
\hline Monensina & 14,07 & $57,91^{\mathrm{b}}$ & 3,88 & 71,98 & 52,13 \\
\hline FAP & 10,95 & $62,12^{\mathrm{ab}}$ & 3,57 & 73,07 & 50,54 \\
\hline \multicolumn{6}{|l|}{ Mombaça } \\
\hline Controle & 23,93 & 56,48 & 4,16 & 80,41 & 62,03 \\
\hline Levedura & 24,16 & 56,79 & 3,83 & 80,95 & 61,06 \\
\hline Monensina & 25,15 & 55,42 & 3,76 & 80,56 & 61,16 \\
\hline FAP & 23,31 & 58,10 & 3,72 & 81,41 & 60,99 \\
\hline \multicolumn{6}{|l|}{ Silagem de Mombaça } \\
\hline Controle & 14,23 & $57,20^{\mathrm{a}}$ & 3,54 & 71,42 & 50,75 \\
\hline Levedura & 14,35 & $56,71^{\mathrm{a}}$ & 3,48 & 71,06 & 50,13 \\
\hline Monensina & 17,09 & $53,47^{\mathrm{b}}$ & 3,35 & 70,56 & 50,41 \\
\hline FAP & 13,94 & $57,96^{\mathrm{a}}$ & 4,21 & 71,90 & 52,02 \\
\hline \multicolumn{6}{|l|}{ Capins } \\
\hline Tifton-85 & $11,20^{\mathrm{c}}$ & $68,37^{\mathrm{a}}$ & 4,15 & $79,60^{\mathrm{a}}$ & $56,98^{b}$ \\
\hline Braquiarão & $10,78^{\mathrm{c}}$ & $60,98^{\mathrm{b}}$ & 3,92 & $71,76^{\mathrm{b}}$ & $50,98^{\mathrm{c}}$ \\
\hline Mombaça & $24,14^{\mathrm{a}}$ & $56,69^{\mathrm{c}}$ & 3,87 & $80,83^{\mathrm{a}}$ & $61,31^{\mathrm{a}}$ \\
\hline Silagem de Mombaça & $14,94^{\mathrm{b}}$ & $56,31^{\mathrm{c}}$ & 3,65 & $71,25^{\mathrm{b}}$ & $50,87^{\mathrm{c}}$ \\
\hline
\end{tabular}


Tabela 2. Degradabilidade in situ da proteína bruta de diferentes gramíneas em bovinos zebuínos recebendo dietas com diferentes aditivos

\begin{tabular}{|c|c|c|c|c|c|}
\hline \multirow{2}{*}{ Item } & \multicolumn{5}{|c|}{ Cinética da degradação1 } \\
\hline & $\mathrm{a}(\%)$ & $\mathrm{b}(\%)$ & $\mathrm{c}(\% / \mathrm{h})$ & $\mathrm{DP}(\%)$ & DE002 (\%) \\
\hline \multicolumn{6}{|l|}{ Tifton-85 } \\
\hline Controle & 5,66 & 86,05 & 3,66 & 91,71 & 61,03 \\
\hline Levedura & 8,43 & 86,38 & 3,15 & 94,81 & 59,62 \\
\hline Monensina & 14,44 & 80,19 & 3,02 & 94,62 & 61,98 \\
\hline FAP & 11,56 & 83,92 & 3,20 & 95,47 & 62,58 \\
\hline \multicolumn{6}{|l|}{ Braquiarão } \\
\hline Controle & 65,31 & 17,68 & $2,43^{b}$ & 82,99 & 75,61 \\
\hline Levedura & 46,89 & 25,56 & $4,37^{\mathrm{ab}}$ & 72,46 & 63,38 \\
\hline Monensina & 78,5 & 9,91 & $4,93^{\mathrm{a}}$ & 88,40 & 85,52 \\
\hline FAP & 65,58 & 23,47 & $2,43^{\mathrm{b}}$ & 89,05 & 73,01 \\
\hline \multicolumn{6}{|l|}{ Mombaça } \\
\hline Controle & 34,12 & 47,83 & 5,28 & 81,95 & 68,73 \\
\hline Levedura & 32,67 & 49,81 & 5,11 & 82,48 & 67,26 \\
\hline Monensina & 35,25 & 46,95 & 4,91 & 82,20 & 68,55 \\
\hline FAP & 34,11 & 48,03 & 4,35 & 82,14 & 66,89 \\
\hline \multicolumn{6}{|l|}{ Silagem de Mombaça } \\
\hline Controle & 58,21 & 25,34 & $2,59^{\mathrm{b}}$ & 83,55 & 72,24 \\
\hline Levedura & 56,99 & 33,49 & $3,87^{\mathrm{ab}}$ & 90,48 & 72,93 \\
\hline Monensina & 48,42 & 30,89 & $6,56^{\mathrm{a}}$ & 79,30 & 71,99 \\
\hline FAP & 55,55 & 25,04 & $3,88^{\mathrm{ab}}$ & 80,59 & 71,45 \\
\hline \multicolumn{6}{|l|}{ Capins } \\
\hline Tifton-85 & $9,73^{\mathrm{d}}$ & $84,39^{\mathrm{a}}$ & $3,27^{b}$ & $94,12^{\mathrm{a}}$ & $61,25^{\mathrm{c}}$ \\
\hline Braquiarão & $64,26^{\mathrm{a}}$ & $19,36^{\mathrm{d}}$ & $3,38^{\mathrm{b}}$ & $83,62^{\mathrm{b}}$ & $74,37^{\mathrm{a}}$ \\
\hline Mombaça & $34,04^{\mathrm{c}}$ & $48,16^{\mathrm{b}}$ & $4,91^{\mathrm{a}}$ & $82,19^{\mathrm{b}}$ & $67,86^{\mathrm{c}}$ \\
\hline Silagem de Mombaça & $54,79^{\mathrm{b}}$ & $28,69^{\mathrm{c}}$ & $4,20^{\mathrm{ab}}$ & $83,48^{\mathrm{b}}$ & $72,15^{\mathrm{ab}}$ \\
\hline
\end{tabular}


Tabela 3. Degradabilidade in situ da fibra em detergente neutro de diferentes gramíneas em bovinos zebuínos recebendo dietas com diferentes aditivos

\begin{tabular}{|c|c|c|c|c|c|}
\hline \multirow{2}{*}{ Item } & \multicolumn{5}{|c|}{ Cinética da degradação 1} \\
\hline & a (\%) & $\mathrm{b}(\%)$ & c $(\% / h)$ & DP (\%) & DE002 (\%) \\
\hline \multicolumn{6}{|l|}{ Tifton-85 } \\
\hline Controle & 3,47 & 75,59 & 4,78 & 79,06 & 56,44 \\
\hline Levedura & 6,22 & 72,29 & 4,15 & 78,5 & 54,56 \\
\hline Monensina & 6,06 & 73,49 & 3,94 & 79,55 & 54,31 \\
\hline FAP & 7,14 & 73,98 & 3,89 & 81,13 & 55,60 \\
\hline \multicolumn{6}{|l|}{ Braquiarão } \\
\hline Controle & 3,38 & 67,81 & 4,10 & 71,20 & 48,98 \\
\hline Levedura & 7,42 & 63,69 & 3,67 & 71,11 & 48,43 \\
\hline Monensina & 9,34 & 62,02 & 4,17 & 71,35 & 51,26 \\
\hline FAP & 6,50 & 65,95 & 3,57 & 72,45 & 48,58 \\
\hline \multicolumn{6}{|l|}{ Mombaça } \\
\hline Controle & 19,74 & 59,68 & 4,05 & 79,41 & 59,68 \\
\hline Levedura & 21,76 & 58,12 & 3,81 & 79,88 & 59,25 \\
\hline Monensina & 21,43 & 56,96 & 3,86 & 78,39 & 58,73 \\
\hline FAP & 22,02 & 58,04 & 3,54 & 80,06 & 59,03 \\
\hline \multicolumn{6}{|l|}{ Silagem de Mombaça } \\
\hline Controle & 10,25 & $60,75^{\mathrm{a}}$ & 3,34 & 71,01 & 48,25 \\
\hline Levedura & 10,16 & $60,32^{\mathrm{a}}$ & 3,37 & 70,48 & 47,79 \\
\hline Monensina & 13,44 & $55,71^{\mathrm{b}}$ & 3,21 & 69,16 & 47,62 \\
\hline FAP & 9,62 & $61,70^{\mathrm{a}}$ & 3,45 & 71,32 & 48,46 \\
\hline \multicolumn{6}{|l|}{ Capins } \\
\hline Tifton-85 & $5,72^{\mathrm{c}}$ & $73,84^{\mathrm{a}}$ & $4,20^{\mathrm{a}}$ & $79,56^{\mathrm{a}}$ & $55,23^{b}$ \\
\hline Braquiarão & $6,50^{\mathrm{c}}$ & $65,08^{\mathrm{b}}$ & $3,82^{\mathrm{ab}}$ & $71,58^{\mathrm{b}}$ & $49,04^{\mathrm{c}}$ \\
\hline Mombaça & $21,23^{\mathrm{a}}$ & $58,20^{\mathrm{c}}$ & $3,81^{\mathrm{ab}}$ & $79,43^{\mathrm{a}}$ & $59,17^{\mathrm{a}}$ \\
\hline Silagem de Mombaça & $10,92^{\mathrm{b}}$ & $59,57^{\mathrm{c}}$ & $3,34^{\mathrm{b}}$ & $70,49^{\mathrm{b}}$ & $48,05^{\mathrm{c}}$ \\
\hline
\end{tabular}

Os capins tifton-85 e Brachiaria apresentaram porcentagens menores da fração solúvel (a) e maiores da fração insolúvel potencialmente degradável (b) da MS e FDN (Tabelas 1 e 3), indicando a necessidade de maior tempo de retenção no rúmen para atingir o máximo de degradabilidade total. Já, a proteína bruta do capim Brachiaria apresentou-se altamente solúvel (64,26\%) (Tabela 2).

Zeoula et al. (2014) observaram que as degradabilidades potencial e efetiva da FDN em amostras de capim Tifton-85 foram mais elevadas $m$ bovinos recebendo dieta com uso de monensina que levedura. Leveduras vivas adicionadas ao rúmen têm sido relacionadas ao aumento da concentração de bactérias celulolíticas, tais como Fibrobacter succinogenes e Ruminococcus flavefaciens melhorando a digestão da fibra (LILA et al., 2006; CHAUCHEYRAS-DURAND et al., 2016). No presente experimento, esse efeito não foi observado uma vez que não houve diferenças nas degradabilidades potencial e efetiva da FDN entre os tratamentos. Inclusive, a monensina promoveu uma menor degradação da fração "b" na silagem de Mombaça em relação aos demais tratamentos.

Não houve diferenças significativas no $\mathrm{pH}$ médio do líquido ruminal entre os diferentes tratamentos $(p>0,05)$, 
mantendo-se valores altos variando entre 6,43 a 6,70 em todos os tempos avaliados, o que demonstra padrões normais para animais alimentados com dieta rica em volumoso. Fereli et al. (2010) também não observaram diferenças no $\mathrm{pH}$ ruminal de bovinos com o uso de levedura e monensina.

A monensina tem sido identificada causar aumento do $\mathrm{pH}$ ruminal em dietas ricas em concentrado (SAFAEI et al., 2014), mas não em bovinos sob pastejo ou em dieta rica em forragem (DEMARCO et al., 2014; VENDRAMINI et al., 2015). Houve diminuição no valor médio do $\mathrm{pH}$ de antes da alimentação $(6,62)$ para $4 \mathrm{~h}$ após $(6,47)$. A concentração de nitrogênio amoniacal no rúmen foi reduzida com a adição de monensina $(13,77 \mathrm{mg} / \mathrm{dL})$ em relação à dieta controle $(16,48 \mathrm{mg} / \mathrm{dL})$ (Tabela 4). Entretanto, pesquisadores não observaram efeitos da monensina na produção de $\mathrm{N}$-amoniacal no rúmen em bovinos (FERELI et al., 2010; VENDRAMINI et al., 2015). Em dieta de baixa qualidade de forragem a adição de levedura tem sido observada causar redução na concentração de $\mathrm{N}$-amoniacal no rúmen (MAO et al., 2013). A maior concentração de $\mathrm{N}$ amoniacal ruminal ocorreu duas horas após a alimentação para todos os tratamentos $(23,84 \mathrm{mg} / \mathrm{dL})$, diminuindo para atingir o menor valor médio em $8 \mathrm{~h}$ após a alimentação $(9,2 \mathrm{mg} / \mathrm{dL})$.

Tabela 4. Valores médios de $\mathrm{pH}$ e concentrações de amônia e de ácidos graxos de cadeia curta no líquido ruminal de bovinos em dietas com diferentes aditivos no rúmen

\begin{tabular}{|c|c|c|c|c|}
\hline \multirow{2}{*}{ Item } & \multicolumn{4}{|c|}{ Tratamentos $^{1}$} \\
\hline & $\mathrm{CON}$ & LEV & MON & FAP \\
\hline $\mathrm{pH}$ & 6,55 & 6,51 & 6,62 & 6,57 \\
\hline Amônia, mg/dL & $16,48^{\mathrm{a}}$ & $15,34^{\mathrm{ab}}$ & $13,77^{\mathrm{b}}$ & $15,02^{\mathrm{ab}}$ \\
\hline \multicolumn{5}{|l|}{$\mathrm{AGCC}$} \\
\hline Acético, mM & $65,98^{\mathrm{a}}$ & $69,54^{\mathrm{a}}$ & $62,07^{b}$ & $68,39^{a}$ \\
\hline Propiônico, mM & $12,49^{\mathrm{b}}$ & $13,65^{\mathrm{ab}}$ & $14,49^{\mathrm{a}}$ & $13,46^{\mathrm{ab}}$ \\
\hline Butírico, mM & 7,84 & 8,08 & 7,62 & 7,66 \\
\hline \multirow[t]{2}{*}{ Total, mM } & $86,32^{\mathrm{b}}$ & $91,28^{\mathrm{a}}$ & $84,00^{\mathrm{b}}$ & $89,51^{\mathrm{a}}$ \\
\hline & \multicolumn{4}{|c|}{$\mathrm{mol} / 100 \mathrm{~mol}-$} \\
\hline Acético & $76,51^{\mathrm{a}}$ & $76,27^{\mathrm{a}}$ & $73,61^{b}$ & $76,44^{\mathrm{a}}$ \\
\hline Propiônico & $14,45^{\mathrm{b}}$ & $14,87^{\mathrm{b}}$ & $17,41^{\mathrm{a}}$ & $15,02^{\mathrm{b}}$ \\
\hline Butírico & 9,04 & 8,85 & 8,98 & 8,54 \\
\hline Acético:propiônico & $5,39^{\mathrm{a}}$ & $5,23^{\mathrm{a}}$ & $4,39^{\mathrm{b}}$ & $5,16^{\mathrm{a}}$ \\
\hline
\end{tabular}

${ }^{1} \mathrm{CON}=$ controle; $\mathrm{LEV}=$ Levedura (Saccharomyces cerevisiae); $\mathrm{MON}=$ Monensina sódica ${ }^{\circledR}$ e FAP (Fator $\left.\mathrm{P}{ }^{\circledR}\right)$.

Valores seguidos por letras diferentes na mesma linha diferem entre si $(\mathrm{P}<0,05)$.

Houve diferenças significativas $(\mathrm{p}<0,05)$ na concentração dos ácidos graxos de cadeia curta no rúmen entre os tratamentos, exceto com ácido butírico (Tabela 4). A adição de monensina promoveu menor produção de ácido acético e maior de propiônico ( $\mathrm{mM}$ e $\mathrm{mol} / 100 \mathrm{~mol}$ ), mantendo menor relação acético:propiônico (4,31) entre os tratamentos $(p<0,05)$. Monensina atua como efeito tóxico a muitas bactérias presentes no rúmen, entretanto, bactérias que reduzem succinato à propionato são mais resistentes à ação da monensina, promovendo aumento na produção de propionato (AZZAZ et al., 2015). Esses 
resultados estão em concordância com os dados obtidos com bovinos e bubalinos com o uso de monensina e levedura (ZEOULA et al., 2011) e, também com bovinos de corte recebendo diferentes níveis de monensina na dieta (VENDRAMINI et al., 2015). A produção total dos ácidos graxos de cadeia curta no rúmen foi maior nos animais que receberam levedura e Fator $P$ $(p<0,05)$ que aqueles que recebendo dieta sem aditivos e com o uso de monensina sódica. Aumento na produção total de AGCC também foi observado com a adição de levedura em dietas com vacas de leite (DOLEZAL et al., 2005) e com ovinos (GALIP, 2006). Houve diferenças entre os tratamentos quanto aos tempos de coleta das amostras ao longo do dia $(\mathrm{p}<0,05)$. Com o ácido propiônico essas diferenças médias observadas ocorreram com os tempos antes da alimentação e oito horas após, e para o ácido butírico, com quatro horas após a alimentação. $\mathrm{O}$ pico produção de produção de total dos
AGCC ocorreu em duas horas após a alimentação. As concentrações de ácidos graxos voláteis no rúmen são mantidas em função da produção pelos microrganismos e absorção pela parede do rúmen e dependem do hábito de alimentação e tipo de alimento ingerido pelos ruminantes. Logo após alimentação há um aumento da produção de AGCC e queda do $\mathrm{pH}$, seguindo de uma diminuição lenta ao longo do dia com restabelecimento próxima a nova alimentação (VAN SOEST, 1994).

Não houve diferença significativa ( $>>0,05)$ entre os tratamentos contagem de Entodinium, Epidinium, Charonina e total por $\mathrm{mL}$ de conteúdo ruminal no rúmen (Tabela 5), corroborando com as observações de que a levedura não produziu efeitos sobre a contagem total de protozoários ciliados no rúmen em estudo in vitro (LILA et al., 2004) e com carneiros em dietas baixa e alta de volumoso (GALIP, 2006).

Tabela 5. Concentração e distribuição genérica da população de protozoários ciliados no rúmen de bovinos zebuínos recebendo dietas com diferentes aditivos

\begin{tabular}{|c|c|c|c|c|c|c|}
\hline \multirow{2}{*}{ Item } & \multicolumn{4}{|c|}{ Tratamentos1 } & \multirow{2}{*}{ Média } & \multirow{2}{*}{ EPM2 } \\
\hline & $\mathrm{CON}$ & LEV & MON & Fator P & & \\
\hline \multicolumn{7}{|c|}{ Concentração (x 104 / mL de conteúdo ruminal) } \\
\hline Entodinium & 21,40 & 20,44 & 18,36 & 20,74 & 20,24 & 1,35 \\
\hline Diplodiniinae3 & $2,19^{\mathrm{b}}$ & $2,57^{\mathrm{ab}}$ & $4,16^{\mathrm{a}}$ & $2,58^{\mathrm{ab}}$ & 2,88 & 0,43 \\
\hline Epidinium & 0,10 & 0,07 & 0,04 & 0,09 & 0,07 & 0,02 \\
\hline Isotricha & $0,04^{\mathrm{ab}}$ & $0,03^{\mathrm{ab}}$ & $0,01^{\mathrm{b}}$ & $0,04^{\mathrm{a}}$ & 0,03 & 0,01 \\
\hline Dasytricha & $0,20^{\mathrm{ab}}$ & $0,31^{\mathrm{a}}$ & $0,18^{\mathrm{b}}$ & $0,32^{\mathrm{a}}$ & 0,25 & 0,03 \\
\hline Charonina & 0,26 & 0,32 & 0,20 & 0,33 & 0,27 & 0,05 \\
\hline Total & 24,18 & 23,74 & 22,96 & 24,10 & 23,7 & 1,68 \\
\hline \multicolumn{7}{|c|}{ Composição (\% da população total de ciliados) } \\
\hline Entodinium & $88,5^{\mathrm{a}}$ & $85,7^{\mathrm{ab}}$ & $83,4^{b}$ & $86,3^{\mathrm{ab}}$ & 86,0 & 1,13 \\
\hline Diplodiniinae & $9,2^{\mathrm{b}}$ & $11,2^{\mathrm{ab}}$ & $14,5^{\mathrm{a}}$ & $10,0^{\mathrm{b}}$ & 11,2 & 1,05 \\
\hline Epidinium & 0,4 & 0,4 & 0,3 & 0,4 & 0,4 & 0,09 \\
\hline Isotricha & 0,2 & 0,1 & 0,1 & 0,2 & 0,2 & 0,04 \\
\hline Dasytricha & $0,8^{\mathrm{b}}$ & $1,3^{\mathrm{ab}}$ & $0,9^{\mathrm{ab}}$ & $1,6^{\mathrm{a}}$ & 1,2 & 0,16 \\
\hline Charonina & 0,9 & 1,2 & 0,9 & 1,5 & 1,1 & 0,16 \\
\hline \multicolumn{7}{|c|}{$\begin{array}{l}1 \mathrm{CON}=\text { controle; } \mathrm{LEV}=\text { Levedura (Saccharomyces cerevisiae); } \mathrm{MON}=\text { Monensina sódica } \AA \text { e Fator } \\
\mathrm{P}(\text { Fator } \mathrm{P} \circledast) ; 2 \mathrm{EPM}=\text { Erro padrão da média. } \\
\text { 3Protozoários pertencentes a subfamília Diplodiniinae incluindo os seguintes gêneros: Diplodinium, } \\
\text { Eudiplodinium, Ostracodinium, Metadinium, Enoploplastron e Polyplastron. } \\
\text { Valores seguidos por letras diferentes na mesma linha diferem entre si pelo teste de } \mathrm{LSD}(\mathrm{P}<0,05) \text {. }\end{array}$} \\
\hline
\end{tabular}


O uso de suplementação com monensina promoveu aumento da concentração de ciliados pertencentes a subfamília Diplodiniinae $\left(4,16 \times 10^{4} /\right.$ $\mathrm{mL})$ em relação a dieta sem aditivos $\left(2,19 \times 10^{4} / \mathrm{mL}\right)$. Com isso houve redução significativa na porcentagem de Entodinium (de 88,5 para 83,4\%) e aumento da Diplodiniinae (de 9,2 para $14,5 \%$ ) com o uso de monensina comparado com a dieta controle. Os animais que receberam $o$ aditivo monensina também apresentaram menor concentração de Dasytricha em relação aos suplementados com levedura e Fator P. Esse efeito confirma parcialmente as observações de Chaudhary et al. (2004) com caprinos quanto a um possível efeito tóxico da monensina sobre os ciliados do rúmen, com os holotricos sendo os mais sensíveis. Outros pesquisadores também observaram redução na contagem de protozoários no rúmen em bovinos e ovinos (MARTINELE et al., 2008; NETO et al., 2009). A redução de ciliados no rúmen devido à adição de monensina promove redução do processo de engolfamento de bactérias por protozoários e aumento na concentração da população de bactérias no rúmen (HRISTOV et al., 2003).

Não houve diferença na composição dos diferentes grupos de ciliados no rúmen com o uso de diferentes aditivos. Os valores obtidos compreendendo $86 \%$ dos pequenos protozoários pertencentes ao gênero Entodinium no rúmen concordam com os achados prévios obtidos com bovinos zebuínos (FRANZOLIN et al., 2010), confirmando a informação que a fauna ruminal de bovinos é constituída pela grande maioria de ciliados entodinios (80-99\%) em diversos sistemas de alimentação e distribuição geográfica (DEHORITY, 2003). Entretanto, Arakaki et al. (2000) observaram redução na composição de Entodinium em bovinos zebuínos mestiços mantidos em pastejo com o uso da monensina mantendo $78,1 \%$ da população total e com a levedura em 69,6\% em relação à dieta controle $(87,7 \%)$. Essa redução foi seguida pelo aumento da porcentagem de Dasytricha. No trabalho, o uso do aditivo Fator $\mathrm{P}$ promoveu o dobro da porcentagem de Dasytricha em relação a dieta sem uso de aditivo, passando de $0,8 \%$ para $1,6 \%$ (Tabela 5 ).

Concluímos que os aditivos avaliados não apresentaram efeitos siginificativos sobre a degradabilidade ruminal nos capins tropicais na forma de feno e de silagem, com exceção da monensina no capim Brachiaria e silagem de Mombaça. Entretanto, os aditivos na dieta alteraram a fermentação e a população de protozoários ciliados no rúmen.

\section{REFERÊNCIAS}

\section{ARAKAKI, L.C.; STAHRINGER, R.C.; GARRETT, J.E.; DEHORITY, B.A. The effects of feeding monensin and yeast culture, alone or in combination, on the concentration and generic composition of rumen protozoa in steers fed on low-quality pasture supplemented with increasing levels of concentrate. Animal Feed Science and} Technology, v.84, n.1-2, p.121-127, 2000 .

AZZAZ, H.H.; MURAD, H.A.; MORSY, T.A. Utility of ionophores for ruminant animals: A review. Asian

Journal of Animal Sciences, v.9, n.6, p.254-265, 2015. 
CHAUCHEYRAS-DURAND, F.; AMEILBONNE, A.; BICHAT, A.; MOSONI, P.; OSSA, F.; FORANO, E. Live yeasts enhance fibre degradation in the cow rumen through an increase in plant substrate colonization by fibrolytic bacteria and fungi. Journal of Applied Microbiology, v.120, n.3, p.560-570, 2016.

\section{CHAUDHARY, U.B.; UPADHYAYA,} R.S.; SINGH, N. Effect of feeding monensin and vitamin e on rumen ciliate population in goats. Indian Journal of Animal Sciences, v.74, n.9, p.980-982, 2004.

\section{DEHORITY, B.A. Rumen}

microbiology. Thrumpton, Nottingham, UK:Nottingham University Press, 2003. $372 p$.

DEMARCO, C.F.; SCHWEGLER, E.; BRAUNER, C.C.; FERRI, E.; HALFEN, J.; FLORIO, G.; FLORIO, D.; PEDROSO, C.E.D.; GONCALVES, F.M.; CORREA, M.N. Monensin controlled-release capsules do not change performance and metabolic profile in unchallenged beef cattle. Acta Scientiae Veterinariae, v.42, n.1245, p.1-6, 2014.

DOLEZAL, P.; DOLEZAL, J.; TRINACTY, J. The effect of saccharomyces cerevisiae on ruminal fermentation in dairy cows. Czech Journal of Animal Science, v.50, n.11, p.503-510, 2005.

FERELI, F.; BRANCO, A.F.; JOBIM, C.C.; CONEGLIAN, S.M.; GRANZOTTO, F.; BARRETO, J.C. Sodium monensin and saccharomyces cerevisiae in cattle diets: Ruminal fermentation, nutrient digestibility and microbial synthesis efficiency. Revista Brasileira de Zootecnia, v.39, n.1, p.183-190, 2010.
FERNANDES, L.B.; FRANZOLIN, R.; FRANCO, A.V.M.; CARVALHO, G.

Aditivos orgânicos no suplemento concentrado de bovinos de corte mantidos em pastagem. Revista Brasileira de Saúde e Produção Animal [online], v.9, n.2, p.231-238, 2008.

FONTY, G.; CHAUCHEYRASDURAND, F. Effects and modes of action of live yeasts in the rumen. Biologia, v.61, n.6, p.741-750, 2006.

FRANZOLIN, R.; ROSALES, F.P.; SOARES, W.V.B. Effects of dietary energy and nitrogen supplements on rumen fermentation and protozoa population in buffalo and zebu cattle.

Revista Brasileira de Zootecnia, v.39, n.3, p.549-555, 2010.

GALIP, N. Effects of dietary saccharomyces cerevisiae live yeast culture supplementation on ruminal digestion and protozoa count in rams fed with diets with low or high ratio forage/concentrate. Revue de Medecine Veterinaire, v.157, n.12, p.607-611, 2006.

GUAN, H.; WITTENBERG, K.M.; OMINSKI, K.H.; KRAUSE, D.O. Efficacy of ionophores in cattle diets for mitigation of enteric methane. Journal of Animal Science, v.84, n.7, p.18961906, 2006.

HRISTOV, A.N.; IVAN, M.; NEILL, L.; MCALLISTER, T.A. Evaluation of several potential bioactive agents for reducing protozoal activity in vitro. Animal Feed Science and Technology, v.105, n.1-4, p.163-184, 2003. 
LILA, Z.A.; MOHAMMED, N.; TAKAHASHI, T.; TABATA, M.; YASUI, T.; KURIHARA, M.; KANDA, S.; ITABASHI, H. Increase of ruminal fiber digestion by cellobiose and a twin strain of saccharomyces cerevisiae live cells in vitro. Animal Science Journal, v.77, n.4, p.407-413, 2006.

LILA, Z.A.; MOHAMMED, N.; YASUI, T.; KUROKAWA, Y.; KANDA, S.; ITABASHI, H. Effects of a twin strain of saccharomyces cerevisiae live cells on mixed ruminal microorizanism fermentation in vitro. Journal of Animal Science, v.82, n.6, p.1847-1854, 2004.

MAO, H.L.; MAO, H.I.; WANG, J.K.; LIU, J.X.; YOON, I. Effects of saccharomyces cerevisiae fermentation product on in vitro fermentation and microbial communities of low-quality forages and mixed diets. Journal of Animal Science, v.91, n.7, p.32913298, 2013.

MARTINELE, I.; EIFERT, E.D.; LANA, R.D.P.; ARCURI, P.B.; D'AGOSTO, M. Effect of monensin and soybean oil on rumen ciliate protozoa and correlation between protozoa with ruminal fermentation and digestive parameters. Revista Brasileira de Zootecnia, v.37, n.6, p.1129-1136, 2008.

MARTINS, A.S.; VIEIRA, P.F.; BERCHIELLI, T.T.; PRADO, I.N.; LEMPP, B.; PAULA, M.C.

Degradabilidade in situ e observações microscópicas de volumosos em bovinos suplementados com enzimas fibrolíticas exógenas. Revista Brasileira de Zootecnia, v.36, n.6, p.1927-1936, 2007.
MITSUMORI, M.; SUN, W. Control of rumen microbial fermentation for mitigating methane emissions from the rumen. Asian-Australasian Journal of Animal Sciences, v.21, n.1, p.144-154, 2008.

MOSONI, P.; CHAUCHEYRASDURAND, F.; BERA-MAILLET, C.; FORANO, E. Quantification by realtime pcr of cellulolytic bacteria in the rumen of sheep after supplementation of a forage diet with readily fermentable carbohydrates: Effect of a yeast additive. Journal of Applied Microbiology, v.103, n.6, p.2676-2685, 2007.

NETO, G.B.; BERNDT, A.; NOGUEIRA, J.R.; DEMARCHI, J.J.A.A.; NOGUEIRA, J.C. Monensin and protein supplements on methane productionand rumen protozoa in bovine fed low quality forage. South African Journal of Animal Science, v.39, n.5, p.280-283, 2009.

ORSKOV, E.R.; DEB HOVELL, F.D.; MOULD, F. The use of the nylon bag technique for evaluation of feedstuffs. Tropical Animal Production, v.5, n.3, p.195-213, 1980.

PIRES, A.J.V.; REIS, R.A.; CARVALHO, G.G.P.; SIQUEIRA, G.R.; BERNARDES, T.F.; RUGGIERI, A.C.; ROTH, M.T.P. Ruminal degradability of dry matter, crud protein, and fiber fraction of silages of corn, sorghum, and brachiaria brizantha.

Arquivo Brasileiro de Medicina Veterinaria e Zootecnia, v.62, n.2, p.391-400, 2010. 
PRADO, I.N.; MOREIRA, F.B.; ZEOULA, L.M.; WADA, F.Y.; MIZUBUTI, I.Y.; NEVES, C.A. Degradabilidade in situ da matéria seca, proteína bruta e fibra em detergente neutro de algumas gramíneas sob pastejo contínuo. Revista Brasileira de Zootecnia, v.33, n.5, p.1332-1339, 2004.

SAFAEI, K.; TAHMASBI, A.M.; MOGHADDAM, G. Effects of high concentrate:Forage ratio diets containing monensin on the management of ruminal acidosis in gezhel lambs. Small Ruminant Research, v.121, n.2-3, p.183-187, 2014.

STATSOFT I. Statistica (data analysis softaware system). Version 11. 2012.

VAN SOEST, P. Nutritional ecology of ruminant. Ithaca:Cornell University Press, 1994. 476p.

VENDRAMINI, J.M.B.; SANCHEZ, J.M.D.; COOKE, R.F.; AGUIAR, A.D.; MORIEL, P.; DA SILVA, W.L.; CUNHA, O.F.R.; FERREIRA, P.D.S.; PEREIRA, A.C. Stocking rate and monensin supplemental level effects on growth performance of beef cattle consuming warm-season grasses.

Journal of Animal Science, v.93, n.7, p.3682-3689, 2015.

WEATHERBURN, M.W. Phenolhypochlorite reaction for determination of ammonia. Analytical Chemistry, v.39, n.8, p.971-974, 1967.

WILLIAMS, A.G.; COLEMAN, G.S. The rumen protozoa. New Yok, USA:Springer-Verlag New York, Inc, 1992. 441p.
ZEOULA, L.M.; BELEZE, J.R.F.; MAEDA, E.M.; SIMIONI, F.L.; GERON, L.J.V.; RIGOLON, L.P. Levedura ou monensina na dieta de bovinos e bubalinos sobre a fermentação ruminal e eficiência microbiana. Acta Scientiarum. Animal Sciences, v.33, n.4, p.379-386, 2011.

ZEOULA, L.M.; DO PRADO, O.P.P.; GERON, L.J.V.; BELEZE, J.R.F.; AGUIAR, S.C.; MAEDA, E.M. Total digestibility and in situ degradability of bulky diets with the inclusion of ionophores or probiotics for cattle and buffaloes. Semina-Ciencias Agrarias, v.35, n.4, p.2063-2076, 2014.

Data de recebimento: 16/08/2016

Data de aprovação: 12/06/2017 